\title{
LAND SLIDE ANALYSIS USING DIGITAL ELEVATION MODELS
}

\author{
Mawardi ${ }^{1)}$, Makmun R. Razali ${ }^{2}$, Cyntia ${ }^{3)}$ \\ ${ }^{122) 3)}$ Program Studi Teknik Sipil, Fakultas Teknik UNIB, Jl. W. R. Supratman, \\ Kandang Limun, Bengkulu 38371, Telp. (0736)344087 \\ email: mawardi001@gmail.com
}

\begin{abstract}
Abstrak
Bencana longsor hampir setiap tahun terjadi di Indonesia, longsor ini jarang yang dapat dideteksi secara dini karena selama ini prediksi kelongsoran lereng adalah sulit. Untuk memprediksi memerlukan perhitungan analisis dan stabilitas lereng secara manual. Proses perhitungan manual ini prosesnya cukup panjang dan lama. Data-data perhitungan dan analisis stabiltas lereng berupa pengukuran lereng, pekerjaan ini cukup melelahkan dan beresiko bagi peneliti, dan juga lingkup lereng yang bisa diukur hanya sempit. Selain data kemiringan lereng, untuk analisis lereng juga memerlukan data-data tanah yang harus diambil sampling dan pengujian di laboratorium geoteknik. Penelitian ini meneliti stabilitas lereng dengan membuat model longsor dengan menggunakan Bencana longsor Digital Elevation Models (DEM), dan program Geoslope. Model lereng dianalisis dari DEM dan analisis stabilitas longsor dengan menggunakan Geoslope. Dari konsep ini diharapkan kita dapat mengana lisis longsor/stabilitas lereng dengan cepat dan akurat tanpa resiko bagi peneliti. Hasil dari pengujian lab diperoleh : kadar air $(\mathrm{wN}), \quad \mathrm{wN} 1=39,47 \%, \quad \mathrm{wN} 1=40,54 \%, \quad \mathrm{wN} 1=38,89 \%$. Berat Jenis Tanah (Gs) berkisar 2,60-2,62, berat volume tanah basah berkisar 14,59-16,16 kN/m 3 , berat volume tanah

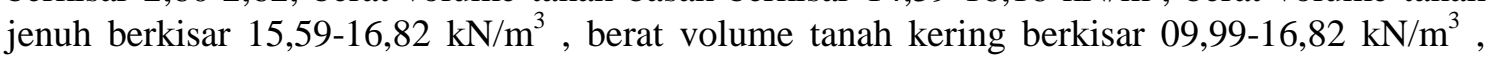
Batas cair tanah berkisar 61,24-66,06 \%, batas plastis tanah berkisar 39,58-44.88 \% , Indek plastis tanah berkisar 21,18-21,66, sehingga tanah ini masuk dalam kategori tanah lempung organik, muka ir tanah pada kedalaman berkisar -0,5m, nilai kohesi (c) berkisar 29,10-34,90 $\mathrm{kPa}$, dan nilai sudut gesek dalam berkisar $\phi 19,51-21,10^{\circ}$, kemiringan lereng berkisar 24-42 dan angka keamanan lereng (FK), pada lereng $1 \mathrm{FK}=1,87$ (lereng aman terhadap bahaya longsor), pada lereng $2 \mathrm{FK}=1,20$ (lereng tidak aman terhadap bahaya longsor), pada lereng 3 $\mathrm{FK}=1,52$ (lereng aman dari bahaya longsor).
\end{abstract}

Kata kunci: digital elevation models, geoslope, stabilitas lereng

\begin{abstract}
Landslides almost every year occur in Indonesia, this rare landslide that can be detected early. because so far the prediction of slope slope is difficult. To predict the calculation requires the analysis and stability of the slope manually. This manual calculation process is quite long and long process. The calculation data and slope stability analysis are in the form of slope measurement, the work is quite tiring and risky for the researcher, and also the scope of the slope that can be measured is only narrow. In addition to slope inclination data, for slope analysis also requires soil data to be sampled and testing in a geotechnical laboratory. This study investigated slope stability by creating landslide models using Digital Elevation Models (DEM), and Geoslope programs. Slope model was analyzed from DEM and landslide stability analysis using Geoslope. From this concept we are expected to analyze landslide / stability slope quickly and accurately without risk for researcher. The results of lab tests were obtained: water content $(w N), w N 1=39.47 \%, w N 1=40.54 \%, w N 1=38.89 \%$. Specific Soil Weight (Gs)
\end{abstract}


ranged from 2.60 to 2.62, wet soil volume weight ranged from 14.59 to $16.16 \mathrm{kN} / \mathrm{m} 3$, the weight of saturated soil volume ranged from 15.59 to $16.82 \mathrm{kN} / \mathrm{m} 3$, the weight of soil volume dried ranged from 09.99 to $16.82 \mathrm{kN} / \mathrm{m} 3$, soil liquid limit ranged $61.26-66.06 \%$, plastic limit of land ranged from 39.58 to $44.88 \%$, soil plastic index ranged from 21.18 to 21.66 , so that the soil is categorized as organic clay soil, the face of the soil at a depth of $-0.5 \mathrm{~m}$, the cohesion value (c) ranges from 29.10 to $34.90 \mathrm{kPa}$, and the frictional angle values in the range 19.51 21.100, the slope of the slope ranges from 24 to 420 and slope safety figures (FK), on slopes 1 $F K=1.87$ (slope safe against landslide hazard), on slope $2 F K=1.20$ (slope unsafe against landslide hazard), on slope $3 F K=1.52$ (the slope is safe from landslide hazards).

Keywords: digital elevation models data, geoslope, slope stability

\section{PENDAHULUAN}

Kabupaten Lebong merupakan bagian dari provinsi Bengkulu, kawasan Lebong merupakan Kawasan perbukitan memiliki topografi yang berlereng-lereng dan berlembah. Kawasan perbukitan lebong merupakan tempat Pembangkit listrik tenaga panas bumi/Geothermal (PLTG) dan sekarang ini lagi tahap konstruksi. Bulan Mei 2016 kawasan perbukitan PLTG ini mengalami longsor. Perbukitan lebong tempat PLTG memiliki ketinggian $\pm 1000 \mathrm{~m}$ dari permukaan air laut. Oleh karena itu, maka banyak jumpai lereng-lereng di sepanjang jalan menuju tempat PLTG ini, yang memiliki potensi longsor.

Longsor yang terjadi banyak disebabkan oleh beberapa hal. Kondisi masyarakat sekitar yang melakukan pembabatan liar di sekitar area lereng serta mendirikan bangunan di atas lereng mengakibatkan penambahan beban lereng. Bencana tanah longsor yang terdapat di lokasi PLTG lebong ini terjadi saat musim penghujan. Hujan merupakan faktor eksternal pemicu terjadinya kelongsoran. Hujan memicu tanah menjadi longsor melalui penambahan beban lereng dan penurunan kuat geser tanah.

Lereng yang tidak mampu menahan pertambahan beban ini mengakibatkan ketidakstabilan pada tubuh lereng itu sendiri sehingga terjadi keruntuhan lereng ke badan jalan. Perhitungan nilai faktor keamanan merupakan cara untuk menganalisis kestabilan suatu lereng dengan menggunakan data sifat fisik tanah, sifat mekanis tanah (geoteknis tanah) dan bentuk geometri lereng (Mawardi dan Shinta Kurnia, 2014).

Model Longsor Akibat Perubahan Iklim Dengan Menggunakan Digital Elevation Models (DEM) dan Geoslope, merupakan pengembangan dari model hitungan manual untuk analisis longsor yang biasa dilakukan selama ini, yang tentunya prosesnya lama dan hasilnya kurang akurat untuk analisis longsor. Dengan pengembangan DEM Geoslope, model ini akan diperoleh kecepatan dan keakurasian dalam analisis model longsor, dan akan mempercepat Update daerah-daerah yang berpotensi longsor akibat perubahan iklim yang ektrim dari pada perhitungan manual.

Berdasarkan pengamatan di lapangan, longsoran yang cukup lebar dan cukup tinggi tebingnya, arealnya luas, terdapat beberapa lokasi disekitar PLTG, yang berpotensi terjadi kelongsoran besar yang serupa. Kondisi ini apabila dengan pengukuran manual sangat menyulitkan mendapatkan data lapangnnnya, dan membahayan saat pengambilan data lapangan tersebut. Oleh karena itu pengembangan dari perhitungan analisis longsor secara manual, sangat tepat dan urgent sifatnya. 
Tujuan penelitian ini memberikan solusi permasalahan sulitnya mendapatkan datadata longsoran dilapangan, faktor kendala alam, serta perhitungan dan analisis longsor membutuhkan waktu yang lama, sehingga kita tidak cepat mendeteksi dini pada suatu lereng

Penelitian ini mengajukan konsep baru model DEM Geoslope ini untuk analisis bahaya longsor/stabilitas lereng untuk mengatasi permasalahan kurang cepat dan analisis stabilitas lereng dengan adanya sulitnya mendapatkan data secaara manual dilapangan untuk data yang akan diolah sebagai data stabilitas lereng. Dengan model DEM Geoslope ini maka akan dapat dengan cepat perhitungan / analisis stabilitas lereng dapat diselesaikan, dan dengan model ini maka areal yang luas dan tinggi tebing tidak akan menjadi masalah. Dengan adanya kecepatan analisis dengan model DEM Geoslope, maka kita dapat dengan cepat meng-update stabilitas lereng pada lerenglereng yang mengalami bahaya longsor. Sebagai studi kasus maka di pakai lokasi PLTG Lebong-Curup yang lerenglerengnya rawan mengalami bahaya longsor.

\section{METODE PENELITIAN}

Penelitian adalah penelitian eksperimental di laboratorium dan di lapangan. Tempat pengujian di laboratorium Geoteknik, Prodi Teknik Sipil, UNIB. Bahan berupa sampel benda ini berupa tanah dari lokasi lereng yang rawan bahaya longsor di lokasi sekitar PLTG Lebong-Curup

Metode analisis stabilitas lereng dengan menggunakan metode Fellenius. Data yang digunakan bersumber dari pengambilan data di lapangan dan di laboratorium, serta data elevasi tinggi lereng, kedalaman muaka air tanah. Penelitian di lapangan menggambil data geometri lereng, mengambil sampel tanah dengan tabung sampling serta menentukan letak koordinat lereng dengan GPS. Untuk pengujian di laboratorium hanya pengujian sampel tanah lereng yang telah diambil dari lapangan.

Sampel diambil di 3 (tiga) titik lereng yang saling berdekatan, lokasi sekitar PLTG Lebong-Curup, posisi koordinat $3^{\circ} 14^{\prime} 18^{\prime \prime}$ S, $102^{\circ} 17^{\prime} 01^{\prime \prime}$ E kemudian sampel berupa tanah di lakukan pengujian properties tanah dan pengujian kuat geser tanah .

Pengujian sampel tanah di laboratorium terdiri dari dua pengujian yaitu pengujian sifat fisis tanah dan pengujian mekanik tanah. Pengujian sifat fisis tanah digunakan untuk mengetahui karakteristik tanah sedangkan pengujian mekanik untuk mendapatkan nilai kuat geser tanah berupa kohesi (c) dan sudut geser dalam $(\varphi)$. Data yag telah didapat lalu dianalisis menggunakan metode Fellinius untuk menghitung faktor keamanan pada masingmasing lereng. Nilai faktor keamanan kemudian dibuatkan kesimpulan terhadap bahaya longsor.

Rangkaian pengujian laboratorium dari penelitian ini adalah pengujian sifat fisis tanah asli. Pengujian dipelakukan pada tanah asli kadar air, berat volume tanah basah, batas-batas aterberg, kuar geser tanah berupa kohesi (c) dan sudut geser dalam $(\varphi)$

Pada penelitian ini jumlah sampel benda uji masing-masing pengujian sebanyak 3 buah. Jenis pengujian sifat fisis meliputi : pengujian kadar air, pengujian berat jenis, berat volume tanah, pengujian batas-batas konsistensi tanah (Atterberg Limit), pengujian analisis saringan, dan di lapangan adalah pengujian kedalaman muka iar tanah, kemiringan sudut lereng, tinggi lereng, dan koordinat GPS lereng.

Pengujian sifat mekanik kuat geser tanah berupa kohesi (c) dan sudut geser dalam $(\varphi)$. 
Jari-jari R kritis longsor diperoleh dari analisis Geoslope untuk mempermudah mendapatkannya. Hasil dari pengujian laboratorium dan data lanpangan kemudian diolah dan di analisis stabilitas lerengnya untuk mengetahui kondisi lereng aman atau tidak aman.

\section{HASIL DAN PEMBAHASAN}

Pada pengujian kadar air, pengujian berat jenis, pengujian batas-batas konsistensi tanah, pengujian analisis saringan, pengujiannya menggunakan sampel benda uji masing-masing sebanyak 3 (tiga) buah benda uji. Berikut adalah hasil pengujian yang dilakukan pada tanah asli sekitar PLTG Lebong-Curup. Lokasi pengambilan Data lapangan, ketinggian dan kemiringan lereng di sajikan dalam tabel 1 .

Tabel 1. Lokasi Pengambilan Data di Lapangan

\begin{tabular}{|c|c|c|c|c|}
\hline No & GPS lokasi & Kemiringan & $\mathrm{h}$ & $\left({ }^{\circ}\right)$ \\
\hline 1 & $\begin{array}{c}3^{\circ} 14^{\prime} 18^{\prime \prime} \mathrm{S}, \\
102^{\circ} 17^{\prime} 01^{\prime \prime} \\
\mathrm{E}\end{array}$ & 11,81 & 7,90 & 42 \\
\hline 2 & $\begin{array}{c}3^{\circ} 14^{\prime} 18^{\prime \prime} \mathrm{S}, \\
102^{\circ} 17^{\prime} 01^{\prime \prime} \\
\mathrm{E}\end{array}$ & 33,59 & 13,66 & 24 \\
\hline 3 & $\begin{array}{c}3^{\circ} 14^{\prime} 18^{\prime \prime} \mathrm{S}, \\
102^{\circ} 17^{\prime} 01^{\prime \prime} \\
\mathrm{E}\end{array}$ & 14,80 & 9,11 & 38 \\
\hline
\end{tabular}

\section{Kadar air asli}

Pengujian kadar air berpedoman pada SNI1965-2008, 2008, Cara Uji Penentuan Kadar Air Untuk Tanah Dan Batuan di Laboratorium, kadar air asli (natural water content test). Sampel benda uji tanah asli, diambil langsung dari lokasi dengan menggunakan tabung sampel dan merupakan tanah tak terganggu. Dari hasil pengujian tanah asli tersebut diperoleh nilai kadar air tanah asli tersebutt $(\mathrm{wN})=$ $39,47 \%, 40,54 \%, 38,89 \%$.
Tabel 2. Hasil Pengujian Kadar Air

\begin{tabular}{|c|c|c|c|c|}
\hline No & Uraian & \multicolumn{3}{|c|}{ Hasil Pengujian } \\
\hline 1 & $\begin{array}{l}\text { Berat cincin (gr) } \\
(\mathrm{W} 1)\end{array}$ & 90 & 90 & 90 \\
\hline 2 & $\begin{array}{l}\text { Berat cawan (gr) } \\
\text { (W2) }\end{array}$ & 44 & 38 & 42 \\
\hline 3 & Tinggi cincin $(\mathrm{cm})$ & 2.11 & 2.11 & 2.11 \\
\hline 4 & $\begin{array}{l}\text { Diameter cincin } \\
(\mathrm{cm})\end{array}$ & 6.35 & 6.35 & 6.35 \\
\hline 5 & $\begin{array}{l}\text { Volume cincin } \\
\left(\mathrm{cm}^{3}\right)(\mathrm{V})\end{array}$ & 66.79 & 66.79 & 66.79 \\
\hline 6 & $\begin{array}{l}\text { Berat tanah basah + } \\
\text { Berat cincin (gr) } \\
(\mathrm{W} 3)\end{array}$ & 196 & 194 & 190 \\
\hline 7 & $\begin{array}{l}\text { Berat tanah basah } \\
(\mathrm{gr})(\mathrm{W} 4) \rightarrow \mathrm{W} 4= \\
\mathrm{W} 3-\mathrm{W} 1\end{array}$ & 106 & 104 & 100 \\
\hline 8 & $\begin{array}{l}\text { Berat tanah kering } \\
+ \text { Berat cawan (gr) } \\
\text { (W5) }\end{array}$ & 120 & 112 & 114 \\
\hline 9 & $\begin{array}{l}\text { Berat tanah kering } \\
(\mathrm{gr})(\mathrm{W} 6) \rightarrow \mathrm{W} 6= \\
\mathrm{W} 5-\mathrm{W} 2\end{array}$ & 76 & 74 & 72 \\
\hline 10 & $\begin{array}{l}\text { Berat isi b } \\
(\mathrm{gr} / \mathrm{cm} 3)\end{array}$ & 1.56 & 1.59 & 1.50 \\
\hline 11 & $\begin{array}{l}\text { Rata-rata Berat isi } \\
\mathrm{b}(\mathrm{gr} / \mathrm{cm} 3)\end{array}$ & 1.547 & 1.547 & 1.547 \\
\hline 12 & $\begin{array}{l}\text { Kadar air }(\%) \\
(\mathrm{W})=\end{array}$ & 39.47 & 40.54 & 38.89 \\
\hline 13 & $\begin{array}{l}\text { Berat isi d } \\
(\mathrm{gr} / \mathrm{cm} 3)\end{array}$ & 1.14 & 1.11 & 1.08 \\
\hline 14 & $\begin{array}{l}\text { Rata-rata Berat isi } \\
\text { kering } d(\mathrm{gr} / \mathrm{cm} 3)\end{array}$ & 1.108 & 1.108 & 1.108 \\
\hline
\end{tabular}

\section{Berat jenis specific gravity (Gs)}

Pelaksanaan pengujian berat jenis tanah asli berpedoman pada SNI-1964-2008, Cara Uji Berat Jenis Tanah. Benda uji untuk pengujian Berat Jenis tanah berupa tanah asli yang gembur yang di SSD-kan (kering permukaan). Tanah gembur ini adalah yang lolos saringan no.4 (diameter butiran tanah $2 \mathrm{~mm}$ ). Tanah ini kemudian lakukan pengovenan selama 24 jam pada suhu berkisar $110^{\circ} \mathrm{C}$. Setelah diuji berat jenisnya tanah asli dan tanah asli Gs pengujian disajikan dalam Tabel 3. 
Tabel 3. Hasil Pengujian Berat Jenis (specific

\begin{tabular}{cc}
\multicolumn{2}{c}{ gravity) Gs } \\
\hline No. & Berat Jenis Tanah (Gs) \\
\hline 1 & 2,62 \\
\hline 2 & 2,62 \\
\hline 3 & 2,60
\end{tabular}

Berdasarkan Tabel 3 terlihat bahwa tanah asli mempunyai berat jenis (Gs) berkisar 2,62 - 2,60 sehingga tanah asli tersebut mempunyi berat jenis (Gs) yang hampir sama dengan simpangan sebesar $0,8 \%$, ratarata berat jenis (Gs) sebesar 2,61, dengan demikian menurut Hardiyatmo 2002, tanah ini diklasifikasikan tanah yang termasuk tanah lempung organik.

\section{Pengujian berat volume basah (berat isi)}

Pengujian berat isi tabah basah mengikuti standar SNI 03-3637-1994, cara pengujian berat volume tanah (berat isi). Benda uji untuk pengujian Berat isi tanah berupa tanah asli dan diambil sampel dari tabuolume tanah yang berupa tabung di hiting isinya, Berat volume tanah basah adalah berat dibagi isi-nya. Untuk mendapatkan berat tanah kering dan berat tanah jenuhnya maka dapat di ketahui dari kadar airnya. Setelah dilakukan pengujian berat volume basah, berat volume kering dan berat volume jenuh, kemudian hasil pengujiannnya disajikan dalam Tabel 4 .

Tabel 4. Hasil Pengujian berat isi basah, kering, dan jenuh.

\begin{tabular}{cccc}
\hline No. & $\begin{array}{c}\text { Berat isi } \\
\text { tanah basah } \\
(\mathrm{b}) \\
\left(\mathrm{kN} / \mathrm{m}^{3}\right)\end{array}$ & $\begin{array}{c}\text { Berat isi } \\
\text { tanah } \\
\text { kering }(\mathrm{d}) \\
\left(\mathrm{kN} / \mathrm{m}^{3}\right)\end{array}$ & $\begin{array}{c}\text { Berat isi } \\
\text { tanah jenuh } \\
\text { air }(\mathrm{sat}) \\
\left(\mathrm{kN} / \mathrm{m}^{3}\right)\end{array}$ \\
\hline 1 & 15,18 & 10,87 & 16,53 \\
\hline 2 & 16,16 & 11,36 & 16,82 \\
\hline 3 & 14,59 & 09,99 & 15,95 \\
\hline
\end{tabular}

Dari pengujian berat isi tanah, dapat dilihat tanah mempunyai berat volume basah berkisar 1,49 $\mathrm{gr} / \mathrm{cm}^{3}$ sampai dengan 1,65 $\mathrm{gr} / \mathrm{cm}^{3}$, mempunyai berat volume kering berkisar $1,02 \mathrm{gr} / \mathrm{cm}^{3}$ sampai dengan 1,16 $\mathrm{gr} / \mathrm{cm}^{3}$, mempunyai berat volume jenuh berkisar 1,03 $\mathrm{gr} / \mathrm{cm}^{3}$ sampai dengan 1,68 $\mathrm{gr} / \mathrm{cm}^{3}$. Berat volume basah hasil pengujian berkisar 1,49-1,65 $\mathrm{gr} / \mathrm{cm}^{3}$ dengan demikian menurut Hardiyatmo 2002, tanah ini diklasifikasikan sebagai tanah lempung sangat organik.

\section{Analisis saringan (sieve analysis)}

Pengujian analisis saringan berpedoman pada SK-SNI-3423-1994, Tata cara uji analisis ukuran butir tanah (Budi, 2011) dan SNI-03-1968-1990, 1990, tentang Metode Pengujian Tentang Analisis Saringan Agregat Halus dan Kasar. Pengujian analisis saringan digunakan saringan no. 200, 100, $50,30,20,10,8,4$ dan PAN. Metode pengayaan ini menggunakan metode basah (wet method). Hasil dari pengujian analisis saringan ini diperoleh bahwa 3 sampel tanah lereng tersebut termasuk ke dalam klasifikasi tanah berbutir halus (lempung) hal ini dikarenakan 50\% sampel yang diayak lewat saringan no.200 (diameter butiran 0,075 mm).

\section{Pengujian batas-batas konsistensi tanah (atterberg limit)}

Pengujian batas-batas konsistensi tanah ini meliputi pengujian batas cair dan batas plastis. Sampel untuk pengujian- pengujian batas cair dan batas plastis menggunakan tanah terganggu yang kering udara dan yang lolos saringan no. 40. Pengujian batas-batas konsistensi tanah ini bertujuan untuk mengetahui besar nilai batas cair \% (LL), batas plastis \% (PL), dan PI (Indeks Plastisitas) tanah. Dari hasil pengujian ini dapat digunakan untuk menentukan sifat dan klasifikasi tanah menggunakan A-line.

\section{Pengujian batas cair (liquid limit test)}

Pengujian batas cair menggunakan standar SNI-1967-2008, Cara Uji Batas Cair Tanah dan SK-SNI-1967-1990, tentang tata cara uji penentuan batas cair dengan alat yang 
disebut cassagrande. Untuk mendapatkan nilai batas cair yitu pada ketukan ke 25 alat cassagrande. Sample yang digunakan 4 sampel. Benda uji yang digunakan berdasarkan kadar air yang ditambahkan naik sedikit demi sedikit atau penambahan berbeda-beda, sehingga nanti dapat ditemukan pada ketukan yang ke 25 dari alat cassagrande, dan ini yang merupakan batas cairnya dari tanah tersebut (dibuat grafik hubungan kadar air dan jumlah ketukan). Pengujian Atterberg Limit menggunakan sampel tanah terganggu. Hasil pengujian lab batas cair dapat dilihat pada Tabel 5.

\section{Pengujian batas plastis (plastic limit test)}

Pengujian batas plastis berpedoman standar SNI-1966-2008, 2008, Cara Uji Batas Plastis dan Indeks Plastisitas Tanah. Perhitungan indek Plastis adalah Batas Plastis dikurangkan Batas Cair (Hardiyatmo, 2002, Das, 1994, Soedarmo, dkk 1993). Cara pengujian batas plastis adalah membuat gulungan-gulungan tanah di atas plat kaca hingga gulungan tanah berdiameter terbentuk $3 \mathrm{~mm}$ dan ketika tanah tepat berada di diameter $3 \mathrm{~mm}$ dan mulai mengalami retak-retak nyata, maka tanah ini sudah dalam kondisi batas plastis-nya. Untuk mengetahui batas plastisnya kemudian sampel tanah ini dilakukan pengujian kadar airnya, yaitu dengan cara sampel gulungan tanah yang retak tersebut diperiksa kadar airnya dengan dimasukan oven pada suhu $110{ }^{\circ} \mathrm{C}$, selama 24 jam, kemudian setelah sampel di oven, sampel ditimbang, untuk mengetahui kadar airnya. Hasil pengujian lab, batas plastis tanah dapat dilihat Tabel 5.

Indeks Plastisitas (Plastisity Index), Perhitungan Indeks Plastisitas setelah pengujian pengujian batas cair dan batas plastis. Nilai Indeks Plastisitas tanah dapat dihitung dengan rumus PI=LL-PL. Nilai hasil perhitungan Indeks Plastisitas tanah ini dapat dilihat pada Tabel 5.

Tabel 5. Hasil Pengujian Atterberg Limit

\begin{tabular}{cccc}
\hline No. & $\begin{array}{c}\text { Batas Cair } \\
(\%)\end{array}$ & $\begin{array}{c}\text { Batas } \\
\text { Plastis (\%) }\end{array}$ & $\begin{array}{c}\text { Indeks } \\
\text { Plastis (\%) }\end{array}$ \\
\hline 1 & 62,70 & 41,48 & 21,22 \\
\hline 2 & 66,06 & 44,88 & 21,18 \\
\hline 3 & 61,24 & 39,59 & 21,66 \\
\hline
\end{tabular}

Dari hasil pengujian batas cair bataspalstis, dan perhitungan indeks plastis, kemudian diplotkan pada diagram A-line, sehingga akan ditemukan letak titik temu garis pada masing-masing sampel lereng. Dan dari diagram tersebut, didapatlah klasifikasi jenis tanah pada masing-masing lereng. Hasil plot di A-Line menunjukkan jenis tanah berdasarkan pengujian Atterberg Limit, dan klasifikasi jenis tanah dari pengujian ini disajikan dalam Tabel 6.

Tabel 6. Klasifikasi Jenis tanah

\begin{tabular}{cl}
\hline No. & Jenis Tanah \\
\hline 1 & Lempung organik \\
\hline 2 & Lempung organik \\
\hline 3 & Lempung organik \\
\hline
\end{tabular}

Hasil pengujian Batas cair, batas plastis, indek plastis, yang di plotkan dalam grafik A-line, di peroleh jenis klasifikasi tanah tersebut kesemuanya menunjukkan jenis tanah lempung organik.

\section{Pengujian kuat geser tanah (direct shear} Test)

Pengujian kuat geser tanah berpedoman pada SNI 2813-2008 tentang Cara pengujian Kuat geser tanah. Untuk mendapatkan parameter kuat geser tanah maka dilakukan pengujian kuat geser tanah dengan alat Direct Shear Test, dilaboratorium Tanah / Geoteknik Prodi Teknik Sipil, Fakultas Teknik Universitas Bengkulu UNIB. Peralatan pengujian pengujian geser langsung meliputi kotak geser dari benda uji yang berbentuk lingkaran dengan diameter 
$6,35 \mathrm{~cm}^{2}$ dengan tinggi $2,11 \mathrm{~cm}$. Pengujian ini dilakukan tanah dalam kondisi jenuh, karena direndam dalam air saat pengujian denan alat Direct Shear Test.

Hasil Pengujian kuat geser langsung menghasilkan nilai kohesi (c) dan sudut gesek dalam $(\varphi)$ yang digunakan dalam analisis stabilitas lereng. Hasil dari pengujian untuk masing-masing lereng dapat dilihat pada Tabel 7.

Tabel 7. Hasil Pengujian parameter kuat geser langsung

\begin{tabular}{ccc}
\hline No. & $\begin{array}{c}\text { Kohesi (kPa) } \\
\end{array}$ & $\begin{array}{c}\text { Sudut gesek } \\
\text { dalam }\left({ }^{\circ}\right) \\
\varphi\end{array}$ \\
\hline 1 & 34,90 & 21,10 \\
\hline 2 & 29,10 & 19,51 \\
\hline 3 & 31,91 & 20,45 \\
\hline
\end{tabular}

Hasil pengujian kuat geser langsung menghasilkan nilai kohesi (c) berkisar 29,1 $\mathrm{kPa}-34,90 \mathrm{kPa}$, Pada tanah ini mempunyai kohesi yang besar dengan demikian maka tanah ini termasuk jenis tanah tanah tanah lempung. Ttanah ini mempunyai sudut gesek dalam $(\varphi)$ berkisar $19,51^{\circ}-21,10^{\circ}$, maka menurut Das (1994), tanah jenis ini termasuk jenis tanah lempung.

Analisis Stabilitas Lereng. Pada Penelitian ini analisis stabilitas lereng menggunakan metode Fellenius. Analisis Stabilitas Lereng metoda Fellenius ini merupakan metode analisis stabilitas lereng yang sederhana cara perhitungannya, sehingga metoda ini sering digunakan dalam perhitunganperhitungan untuk analisis stabilitas lereng, guna untuk dapat menentukan faktor keamanan lereng.

Berdasarkan pengujian sifat-sifat properties tanah dan sifat mekanik tanah maka dapat diketahui bahwa tanah di sekitar lokasi PLTG Lebong-Curup ini merupakan tanah lempung organik, dengan demikian maka dapat ketahui bahwa model kelongsorannya adalah model busur dan dapat di analisis stabilitas lerengnya dengan metoda Fellenius, untuk angka keamanan lerengnya. Untuk data kedalaman air tanah di dapatkan dari pengujian bor atau sondir. Pada lokasi ini kedalaman muka air tanahnya cukup dangkal berkisar -0,50 $\mathrm{m}$.

Berdasarkan data propertis tanah dan data kuat geser tanah hasil pengujian lab di atas, dan setelah dilakukan perhitungan dan analisis stabilitas lereng maka diperoleh angka keamanan lereng. Hasil perhitungan angka keamanan lereng dapat dilihat pada Tabel 8.

Tabel 8. Hasil perhitungan angka keamana lereng metoda Fellenius.

\begin{tabular}{|c|c|c|c|c|c|}
\hline \multirow[b]{2}{*}{ No. } & (c) & $(\varphi)$ & $(\mathrm{b})$ & $\left(\begin{array}{l}\text { sat } \\
\text { ) }\end{array}\right.$ & \multirow[b]{2}{*}{$(\mathrm{FK})$} \\
\hline & $(\mathrm{kPa})$ & $\left({ }^{\circ}\right)$ & $\left(\mathrm{kN} / \mathrm{m}^{3}\right)$ & $\begin{array}{c}(\mathrm{kN} / \mathrm{m} \\
3\end{array}$ & \\
\hline 1 & 34,90 & 21,10 & 15,18 & 16,53 & 1,87 \\
\hline 2 & 29,10 & 19,51 & 16,16 & 16,82 & 1,20 \\
\hline 3 & 31,91 & 20,45 & 14,59 & 15,95 & 1,57 \\
\hline
\end{tabular}

Tabel 8, hasil perhitungan angka keamanan lereng metoda Fellenius berkisar antara 1,20-1,87. Menurut Fellenius lereng ini termasuk lereng yang berpotensi longsor inggi atau lereng tidak aman terhadap bahaya longsor, karena Faktor keamanan ada yang $(\mathrm{FK}) \leq 1,5$. Menurut Hardiyatmo 2002, pada lereng $1 \mathrm{FK}=1,87$ berarti lereng aman terhadap bahaya longsor, pada lereng $2 \mathrm{FK}=1,20$ berarti pada lereng ini tidak aman terhadap bahaya longsor, pada lereng $3 \mathrm{FK}=1,52$ ini berarti lereng aman dari bahaya longsor.

Dari Tabel 8 terlihat bahwa semakin besar berat volume tanah basahnya maka semakin turun angka keamanan lerengnya. Semakin besar berat volume tanah jenuhnya maka semakin turun angka keamanan lerengnya. Semakin besar nilai kohesinya maka semakin besar pula angka keamanannya. 
Semakin besar sudut gesek dalamnya maka semakin besar pula angka keamanannya.

\section{KESIMPULAN}

Berdasarkan hasil pengujian di laboratorium disimpulkan:

1. Pengujian tanah asli didapat kadar air $(\mathrm{wN}), \quad \mathrm{wN} 1=39,47 \%, \quad \mathrm{wN} 1=40,54 \%$, $\mathrm{wN} 1=38,89 \%$.

2. Berat Jenis Tanah (Gs) berkisar 2,602,62 , berat volume tanah basah berkisar $14,59-16,16 \mathrm{kN} / \mathrm{m}^{3}$,

3. Berat volume tanah jenuh berkisar 15,59 $16,82 \mathrm{kN} / \mathrm{m}^{3}$, berat volume tanah kering berkisar 09,99-16,82 kN/m ${ }^{3}$,

4. Batas cair tanah berkisar $61,24-66,06 \%$, batas plastis tanah berkisar 39,58-44.88 $\%$, Indek plastis tanah berkisar 21,1821,66, sehingga tanah ini masuk dalam kategori tanah lempung organik,

5. Muka ir tanah pada kedalaman berkisar 0,5m, nilai kohesi (c) berkisar 29,10$34,90 \mathrm{kPa}$, dan nilai sudut gesek dalam berkisar $\phi 19,51-21,10^{\circ}$,

6. kemiringan lereng berkisar $24-42^{0}$ dan

7. Angka keamanan lereng (FK), pada lereng $1 \mathrm{FK}=1,87$ (lereng aman terhadap bahaya longsor), pada lereng $2 \mathrm{FK}=1,20$ (lereng tidak aman terhadap bahaya longsor), pada lereng $3 \mathrm{FK}=1,52$ (lereng aman dari bahaya longsor).

\section{DAFTAR PUSTAKA}

Budi, G.S., 2011, Pengujian Tanah di Laboratorium, Graha Ilmu, Yogyakarta.

Das, B.M. 1994. Mekanika Tanah (Prinsip-Prinsip Rekayasa Geoteknis) Jilid II, Erlangga, Jakarta.

Hardiyatmo, H.C., 2002, Mekanika Tanah I, Gadjah Mada University Press, Yogyakarta.
Hardiyatmo, H.C., 2010, Stabilisasi Tanah untuk Perkerasan Jalan, Gadjah Mada Universi3ty Press, Yogyakarta.

SNI-03-3438-1994, 1994, Tata Cara Pembuatan Rencana Stabilisasi Tanah dengan Semen Portland untuk Jalan, Pusjatan Balitbang PU.

SNI-03-1968-1990, 1990, Metode Pengujian Tentang Analisis Saringan Agregat Halus dan Kasar, Pusjatan Balitbang PU.

SNI-03-1744-1089, Metode Pengujian CBR Laboratorium, Pusjatan Balitbang PU.

SNI-1742-2008, 2008, Cara Uji Kepadatan Ringan untuk Tanah, Badan Standardisasi Nasional.

SK-SNI-3423-1994, Cara Uji Analisis Ukuran Butir Tanah, Badan Standardisasi Nasional.

SNI-1964-2008, 2008, Cara Uji Berat Jenis Tanah, Badan Standardisasi Nasional.

SNI-1965-2008, 2008, Cara Uji Penentuan Kadar Air Untuk Tanah dan Batuan di Laboratorium, Badan Standardisasi Nasional.

SNI-1966-2008, 2008, Cara Uji Batas Plastis dan Indeks Plastisitas Tanah, Badan Standardisasi Nasional.

SNI-1967-2008, 2008, Cara Uji Batas Cair Tanah, Badan Standardisasi Nasional.

SK-SNI-1967-1990， 1990， Cara Uji Penentuan Batas Cair dengan Alat Cassagrande, Badan Standardisasi Nasional.

SK-SNI-2813-2008, 2008 Cara pengujian Kuat geser tanah, Badan Standardisasi Nasional.

$\begin{array}{cclr}\text { SK-SNI 03-3637-1994, 1994, } & \text { Cara } \\ \text { pengujian berat isi, } & \text { Badan } \\ \text { Standardisasi Nasional. } & & \end{array}$

